\title{
Una experiencia artística con tierra, barro y cerámica
} An artistic experience with earth, mud and ceramics

Ricard BALANZÀ. Universitat Jaume I. ricardbalanza@gmail.com

Resumen: ¿Qué es la cerámica? ¿Qué nos enseña de nosotros? ¿Está presente en nuestro entorno próximo y lo dota de identidad? ¿Qué de interés nos puede ofrecer en el ámbito educativo de primaria? ¿Qué campos de la expresión artística puede favorecer? Son algunas de las preguntas y reflexiones planteadas que motivan este ejercicio y tratamos de averiguar.

Los alumnos de tercero de Magisterio realizan dos piezas cerámicas utilitarias de distinto método de conformación y acabado, reflexionando sobre la educación artística, la creación y los procesos propios de la cerámica.

Para elaborarlas, se ha completado un proceso íntegro cerámico; partiendo de bocetos previos con una base gráfica tanto de forma como de texturas o motivos, con especial énfasis en los trazos básicos del dibujo en la infancia, su asimilación y translación al volumen (que ofrecen una enorme cantidad de recursos y posibilidades), el modelado en arcilla roja en masa plástica, la aplicación de engobes de una gama elemental de colores, la imprescindible cocción y su transformación metamórfica.

Se pretende, con este ejercicio, desarrollar la expresión artística mediante materiales y técnicas primigenias de nuestra historia, así como la percepción y la sensibilidad estética colectiva e individual, siempre des de un contexto universitario con enfoque a la enseñanza primaria y un alumnado en pleno desarrollo de conocimientos centrados en la exploración, la experimentación y la creación.

Palabras clave: arte, cerámica, arcilla, educación artística, cultura, infancia

Abstract: What is ceramics? What does it teach us about us? Is it present In our nearby environment and endows it witch identity? What interest can you offer us 
in the primary school? What fields of artistic expression can you favour? These are some of the questions and reflections raised that motivated this exercise and we try to find out.

The third-party students of the Magisterium perform two utilitarian ceramic pieces of different method of forming and finishing, reflecting on artistic education, creation and ceramics own processes.

To make them, a complete ceramic process has been completed; staring from previous sketches witch a graphic base of botch shape and textures or motifs, with special emphasis on the basic traces of drawing in childhood, its assimilation and translation into volume (which offer an enormous amount of resources and possibilities), the modelling in red clay in plastic mass, the application of engobes of an elementary range of colours, the essential cooking and its metamorphic transformation.

It is pretend, with this exercise, to develop artistic expression through materials and techniques of our history, as well as perception and collective and individual aesthetic sensibility, always from a university context with a focus on primary education and a student in the midst of the development of knowledge focused on exploration, experimentation and creation.

Keywords: art, ceramics, clay, art education, culture, infancy

\section{Introducción}

La presente práctica se ha desarrollado con alumnos de tercero de grado de Maestro de Educación Primaria durante el curso 2019-2020, en la asignatura de Didáctica de las Artes Plásticas I, de la Facultad de Ciencias Humanas y Sociales de la Universitat Jaume I de Castelló. El perfil del estudiantado -78 en total- es variado y mayoritariamente femenino, con una media de edad de 23 años, y con conocimientos muy básicos en el ámbito artístico tanto en la teoría como en la práctica, salvo algunas excepciones, que cuentan con formación en el campo creativo; como teatro, arte urbano, creación efímera o diseño gráfico, y que se ha constatado en el desarrollo de sus trabajos.

Durante el curso nos ha interesado desarrollar una amplia diversidad de técnicas, muy centradas en lo manual y lo gestual, que vertebrasen la expresión emocional, todas ellas elementales en entornos escolares pero que se han acrecentado en dificultad de planteamiento y de aportación personal de investigación, según el avance de los ejercicios. Paralelamente a los contenidos teóricos y las técnicas plásticas desarrolladas se ha motivado un sentido crítico, estético y sensible con el debate y análisis de obras de arte contemporáneo y su diálogo entre lenguajes 
y disciplinas. Salvaguardando y desarrollando como nos señala Isabel Cabanellas (2002), el poder de armonizar, pues: "la armonía estética es una forma de energía producida por la vida, una emanación interior, una fusión con lo otro, o con los otros, una capacidad de resonancia, una emoción en un determinado dominio de la vida que hay que mantener y respetar con una comprensión justa de su complejidad y de su sutileza" (p.57).

Asimismo, tres han sido los ejes principales en esta materia: un aprendizaje teórico general de la educación artística y de las artes visuales, la puesta en práctica de estos con distintas técnicas plásticas mediante procesos, investigación y experimentación individual y colectiva, y una noción perdurable y paralela de mirar el entorno próximo a través del arte. Una visión especialmente a través de la obra de artistas contemporáneos pertenecientes o vinculados al País Valenciano, que representen un empuje creador que irradie el ritmo del momento, vitales, aliados del viento y alejados de esos "pintores y escultores, ciertamente "vivientes", pero de una más que dudosa actualidad: epígonos de un academicismo anacrónico o "morralla" parasitaria de nuestros autóctonos" (Fuster, 2015, p.202) de siglos pasados.

De modo que la cerámica nos resultaba significativa en este recorrido educativo, por tratarse de un sector productivo tan importante en la zona, que enlaza también con la herencia histórica; que recorre desde los restos hallados en los yacimientos íberos, pasando por las manufacturas de la Real Fábrica de l'Alcora, hasta la cerámica contemporánea o de creación. Acrecentado este interés por el hecho de disponer el departamento de un aula adecuada para esta disciplina artística, donde se imparte como asignatura optativa para el alumnado de Educación Infantil, en la que se dispone de diferentes hornos, materias, materiales, herramientas, etc.

La práctica en cuestión ha consistido en la realización de dos piezas cerámicas por distinto modo de conformado; uno mediante pellizcos partiendo de una bola de barro y otro con la superposición y acumulación de cilindros. El primero con mayor concepción concéntrica y el segundo excéntrica. Para ello se han dibujado previamente 10 bocetos, en los que se ha buscado diferentes diseños formales y de textura, todos ellos utilitarios, "en los cuales la función y la estética se entrelacen, resultando las bases de propuestas que satisfagan igualmente, en respuesta a sus particulares poéticas, aquellas otras exigencias pluralmente funcionales, internas a su respectivo proyecto y finalidad" (De la Calle, 1999, p.15). Además, la reflexión en torno a este sentido de arte y función, la obsolescencia programada de los objetos de la cotidianidad y los materiales que nos rodean.

\section{Marco teórico}

Nos ha interesado abordar la cerámica como una disciplina artística más, acercándonos de manera breve, pero tratando de sacar sustancialmente aquello que de interés articula nuestra materia; la creación con la mater materia-la tierra, el 
barro- en el aprendizaje escolar. Una dimensión estética y educativa unida con el valor plástico que nos puede aportar este arte del fuego, entrelazando razón con intuición y placer. Si bien el aprendizaje en el arte es consustancialmente complejo, es al fin peculiaridad indisociable nuestra como especie, y desde que nacemos debemos ser educados en esta complejidad, ligando juegos con cultura. Es aquí tema esencial articular y dejar libertad, para hacer vivir todas las posibilidades del ser humano (Cabanellas, 2002) y así se plantea esta actividad, uniendo creación y función, mediante la cerámica, entendida según el propio Vicent (1984) como un arte "que envuelve, pero no acaba de cerrar de todo un vacío" (p.5). En este retorno al origen, se pone en valor el vaso primitivo, porque "desde aquel tiempo hasta ahora en cerámica sólo han cambiado los contenidos, [...] por bien que en ellos continua la tradición de naturalidad de cualquier artesano, el humilde amor del artista que juega con tierras y las transforma en ideas o en sensaciones mediante el fuego. Nada hay más cosmológico ni presocrático: la tierra, el agua, el fuego y el aire. Tampoco existe nada más visualmente fecundo" (Vicent, 1984, p.5) Y toda cosmogonía se deja seducir por el mito y este enturbia -aquí podríamos establecer una relación entre la cerámica y los plásticos, en una perorata de sostenibilidad, urbanidad y devenir confuso- y estimula una memoria, que queda impregnada en el barro, bien por nuestras manos o por el eco de los tiempos, como ojos entornados mirando hacia atrás, pues este material maleable y generoso permite la rectificación, el esbozo y la prueba, o así se argumenta por su discutible cercanía a la naturaleza (Yvars, 2011), pero que la química matérica viene a alterar, estableciendo su juicio metamórfico. Es entonces cuando nos aborda una construcción de evocación, una cierta nostalgia que nos apela en el significado de la pervivencia de la antigüedad y su lugar en la recuperación de la memoria histórica, intuyendo "un vital desasosiego ético, ya que la antigüedad representa una herencia, una tradición cultural con la que se han de rendir cuentas. Una decisión que cada época ha de asumir a partir de la sensibilidad que le atañe" (Yvars, 2012, p.13).

Partiendo de esta necesidad de conocimiento y del saber de la base cultural histórica, tratando de extender a la vez la alfabetización visual, se aborda el último bloque del curso; el entorno cercano a través del arte, en el que la mirada próxima y local, junto a la patrimonial, se relacionan con la escuela. La amplia tradición artística del País Valenciano aborda también el desarrollo de la cerámica, siendo reflejo de valores estéticos arraigados que unidos a la vanguardia creativa nutren a las enseñanzas de una herencia y de la consecución de nuevos aprendizajes y avances. Por ello el desarrollo de la expresión artística mediante el barro -y su posterior cocción convirtiéndolo en cerámica-interrelaciona el aprendizaje; principalmente mediante este material básico -bastante presente en la infancia, de modo universal-y sus técnicas, haciendo al alumnado protagonistas activos, explorando, experimentando y creando, y por otro lado la importancia estratégica de proyectar los tiempos y finalmente fomentar el conocimiento y la sensibilidad de este patrimonio en cerámica; artístico y cultural. 
Esta herencia resultado del paso de milenios de evolución es cavilada por la creación de artistas y artesanos, pues las preguntas esenciales siguen siendo las mismas desde su origen, si bien las respuestas nunca se pueden asir. Destacan en el siglo XX: Alfons Blat Monzó (Benimàmet, 1904-València, 1970); Antonio Peyró Mezquita (Onda, 1881-València, 1954); Salvador Sanz Faus (Vilamarxant, 1914-1997); Manuel Safont Castelló (Onda, 1928-2005) o Arcadi Blasco Pastor (Mutxamel, 1928-Majadahonda, 2013); y ya en la contemporaneidad, dentro o fuera del estricto ámbito cerámico: Enric Mestre Estellés (Alboraia, 1936); Mercedes Sebastián (València, 1952); Carmen Ballester (Onda, 1957); Xavier Montsalvatje (Godella, 1964); Miquel Navarro (Mislata, 1945); Carmen Calvo (València, 1950) o Evarist Navarro (Castelló de Rugat, 1959-2014).

Si bien, en la obra de estos tres últimos, la materia cerámica resulta "un elemento expresivo más -que manipulan a su antojo-, sin dejarse llevar por las servidumbres de la técnica, cuya rigidez ortodoxa en múltiples ocasiones sirve de freno para la creatividad" (Pérez, 1999, p.85). La cosmogonía de Miquel Navarro emerge del barro de la huerta de Mislata, de acequias que vislumbran su devenir en urbanidad, cuyas manos ameradas de tierra y agua atestiguan la constante mutabilidad de todo lo existente, poniendo fin -si lo hubiese- a cualquier "anhelo trascendente de fijación perpetua" (Ferrer, 2016, p.55). La artista Carmen Calvo indaga en la memoria simbólica de los objetos y como estos nos identifican y significan: cual fantasmagoría pasa por su paleta compuesta por un sinfin de técnicas en las que bucea y elige en cada momento las más sugerentes, atrayéndole especialmente la sensualidad táctica del barro, que le hace "zambullirse y navegar por mares primigenios" (Calvo, 1999, p.127). La obra de Evarist Navarro nos sacude para apreciar nuestro vacío y plenitud, desde un latido que se sitúa en el fondo del muro, en cuya carnalidad balbucea el sentido de un habla elemental; lo vivo es el "latido arrítmico que nos arrastra por un territorio palpitante en el que cada uno tiene su lugar ya que todos los lugares imaginables son el centro de una imposibilidad central" (Pérez, 1992, p.35).

Así, cualquier creación verdadera en deriva de la eterna metamorfosis cultural, que captura y retiene momentáneamente aquello que se nos muestra en su engañosa quietud "rehúye, por serle imposible, quedar confinada en lo finito, paralizarse en sí; está hambrienta de infinitud -es esencialmente transitoria, circunstancial, ocasional. Así, puede quedar, cuanto más, satisfecha, saciada, más su apetito, tarde o temprano, volverá a despertarse" (Ferrer, 2019, p.73).

\section{Análisis del desarrollo de la acción educativa}

El ejercicio que ha constado de un mes de duración se ha divido en cuatro fases: (1) en primer lugar, una sesión teórica donde se ha mostrado el interés histórico y didáctico del barro y la cerámica, como "huellas de una oculta memoria social de la humanidad" (Yvars, 2012, p.11) en su relación con lo local y lo global y con 
obras de artistas o ceramistas significativos que han trabajado con este material, relacionándolo con los debates discursivos de actualidad. (2) En segundo lugar, una lección de trabajo previo y preparación con bocetos y apuntes gráficos, de formas funcionales y con las posibilidades expresivas propias del dibujo infantil, clasificadas por la psicóloga Rhoda Kellogg (2003), que emplaza "los garabatos que constituyen los cimientos del arte, y su importancia reside en que permiten una descripción detallada y global del trabajo de los niños pequeños" (p.67). Una reflexión plástica del trazo y del dibujo, que unidos a la forma nos marca la deriva donde a "la identificación de los motivos que definen una imagen -iconografía- se añaden los significados consensuados por la representación tradicional iconología" (Yvars, 2012, p.11). (3) En tercer lugar, tres sesiones de taller para confeccionar las piezas de barro, modelando cada día una con un proceso diferente y la última sesión para trabajar, ya en dureza de cuero, la aplicación de engobes, texturas y acabados, y dejar que sequen bien antes de cocer en monococción. (4) Y por último, en la clase final se han entregado las memorias del proceso de la práctica y junto con las reflexiones personales surgidas de esta se ha realizado una puesta en común de los resultados a modo de conclusión, y un debate sobre la creación artística en todas las disciplinas que tanto en la contemporaneidad y en

las sociedades arcaicas como en cualquier otro lugar, la cultura se constituye y se renueva gracias a las experiencias creadoras de algunos individuos. Pero por gravitar la cultura arcaica en torno a los mitos y porque en ellos ahondan continuamente los especialistas de lo sagrado, dándoles interpretaciones nuevas, la sociedad entera se ve arrastrada hacia los valores y los significados descubiertos y transmitidos por ese puñado de individuos. (Eliade, 2006, p.142-143)

Para la realización de estas piezas se ha optado por dos procesos contrapuestos de modelado en su concepción, ambos por su interés en el desarrollo primigenio de la cerámica, hallados en incontables culturas. El modelado con pellizcos y el modelado con rollos o cilindros ofrecen un básico modo de conformado, muy sencillo y con unas posibilidades plásticas interesantes tanto en su estructura como en su superficie, por la gestualidad que impregnan los dedos, además de tener ambos una escala humana según las manos de cada alumno y la sincronización de estas. A la vez que se parte de aquella máxima fundamental de la Bauhaus donde el planteamiento de desarrollo de la creatividad es indisociable al trabajo y que "los planteamientos del profesor nunca se imponen a los estudiantes" (Gropius, 2019, p.12), descartando la limitación, sino que deben servir de estímulo para que el estudiante descubra sus propias capacidades

El proceso para el modelado con pellizcos es el siguiente: se compacta una bola de arcilla de un tamaño que se acople a la mano en posición cóncava - con esta mano mantendremos cogida la pieza mientras que la trabajaremos con la otra-, insertamos hasta la mitad de la bola el dedo gordo y lentamente, manteniendo este dedo en el interior vamos ejerciendo una suave presión entre este dedo y los otros, que se mantendrán rectos en todo momento. Vamos girando la bola a la vez que 
damos presión y así abrir la oquedad primera, generando un tipo de bol que adoptará la forma de la presión aplicada en según qué parte y dirección -generalmente hacia arriba y hacia fuera. De este modo podemos conseguir piezas muy finas y delicadas, rectificando en todo momento las irregularidades si se quiere conseguir mayor uniformidad, aplicando sin excesiva rapidez, en todo momento, la presión y la humedad necesaria para no perder plasticidad, pues esta se va perdiendo en el proceso de conformado y aparecen cuarteos o grietas, encontrándose así con las características propias del barro.

Para modelar con rollos o churros hemos seguido la metodología siguiente: de una porción de arcilla preparamos varias bolas con las manos, las hacemos rodar en vaivén sobre la mesa manteniendo rectos y unidos los dedos, ejerciendo presión de dentro hacia fuera, consiguiendo realizar los rollos. Para la base de la pieza enrollamos en espiral un rollo y así conseguir una superficie, si bien también puede servir para paredes, y con una rasqueta puede alisarse su superficie y conseguir que se una bien la masa. Para elevar las paredes hay que superponer rollos, uno sobre otro, y para asegurarnos que se unan correctamente se aplica entre ellos un poco de barbotina -la misma pasta en estado líquido-o rallamos levemente la superficie de contacto con un punzón y acariciándola con el dedo mojado aplicamos la mínima agua y humedad. Así se pueden repetir los pasos hasta conseguir la forma deseada, teniendo en cuenta el peso de las partes superiores y la resistencia, finalmente se puede dejar vistos los rollos o alisar su superficie.

De modo que la concreción de la forma, buscada con un material blando o duro dependiendo de su contacto con las manos, abarca toda una concepción de límites externos -en cuanto a acción se refiere (Kandinsky, 1996). Forma como delimitación, de permanencia abstracta, en cuanto se recorta en el espacio y es objeto material, y en que no tiene porqué definir un cuerpo real reconocible o mimético, influenciado por la geometría. Se empuja así al alumnado a plantearse si sus obras dependen de sus ojos o de sus manos, pues nos dice John Berger (2017) que las que la imaginación produce existen más allá de una soledad personal, que también es histórica, y “a veces, la visión de una sola imaginación puede sobrepasar las formas sociales de la cultura existente, incluyendo la forma social del arte" (Berger, 2017, p.182).

La búsqueda, en todo momento, por un resultado donde predominase el gesto y un aspecto natural y terroso no excesivamente conformado, nos llevó a elegir una pasta de arcilla roja, con un porcentaje importante de óxido de hierro y de baja temperatura. Si bien todo el trabajo de conformado de ambas piezas ha sido a mano - pensar con las manos. Para los elementos decorativos y de grafismo sí se han utilizado múltiples herramientas y utensilios, como pudieran ser estecas, palitos de modelar, alambres, cuerdas, listones de madera u objetos propios como llaves, tapas de rotulador o pulseras. 
Para hacer hincapié en la necesidad constante de reflexión y visión crítica del trabajo realizado, no solo mediante el proceso sino también a posterior, cuenta la entrega de la práctica con una reflexión personal, en la que se expone de manera escrita aquello que al alumnado le resulta particularmente interesante; bien por su experiencia propia en la realización o por como aplicarían estos conocimientos como futuros docentes de primaria, proyectándose en el futuro como maestros. Tanto el alumnado como "las sociedades no se conocen viendo una sola cara, sino que es necesario verlas todas para conocerlas en sentido global" (Alfaro, 2015, p.25). También otros puntos a tratar que pudieran ser: referentes, creatividad, conceptos o citas, su relación con la cultura visual y con los debates propios de la contemporaneidad en el ámbito escolar, siempre "entre el hecho complementario de articular y dejar libre, para hacer vivir todas las potencialidades del ser humano" (Cabanellas, 2002, p.52). Para ello es fundamental fomentar el uso de vocabulario y palabras adecuadas en el ampliar de saberes del alumnado y conocer las múltiples acepciones del lenguaje aplicadas en la enseñanza artística, pues los límites del lenguaje son los del conocimiento, aceptado el deslizamiento y mestizaje de conceptos pues "un concepto se puede deslizar sobre otro relacionado y producir un cambio de perspectiva y hasta una nueva percepción" (Cabanellas, 2002, p.55).

A continuación, analizamos los resultados, mediante una selección representativamente escasa: cinco piezas- pero cuya interpretación presenta un interés educativo y creativo, de elementos destacados. Para ello hemos partido de la relación del trabajo personal de reflexión del alumnado con sus piezas y de nuestro interés como docente y artista plástico, valorando su creación en profundidad, pues como nos recuerda Yvars (2012): "no nos podemos conformar con la sorpresa... Hemos de extraer de la obra de arte valores de vida: la belleza, el conocimiento de la forma y el sentimiento" (p.11). Esta elección nos ayuda a entender la mirada y capacidad del estudiantado, sus influencias y referentes. Y si de educación artística hablamos ¿qué hay de "la elección de la línea, el ritmo vibrante y la serenidad evocadora de eternidad e infinitud, en una suerte de afinidad que, cuando se habla de arte, puede ligar imágenes distantes por siglos y desde alejadas culturas?" (De la Villa, 2019, p.3).

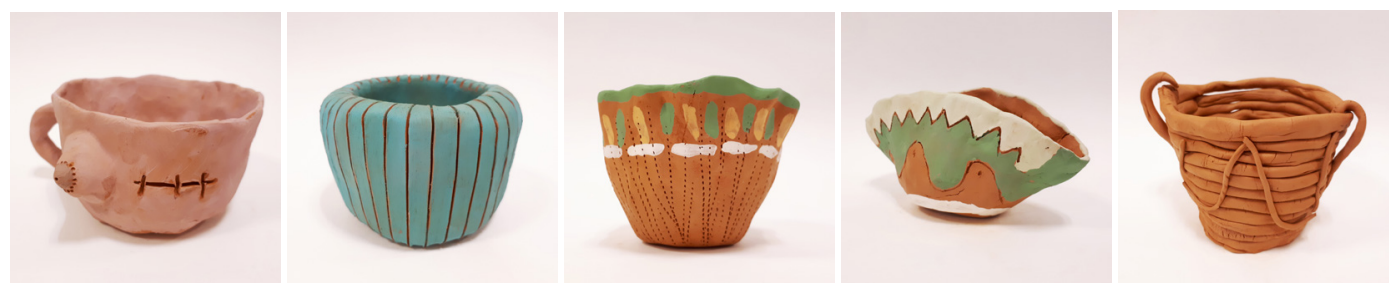

Figuras 1, 2, 3, 4 y 5

Vemos en la Figura 1 una variedad de taza, en ella se alude al cáncer de mama y a la mastectomía, el diálogo con la enfermedad sirve para tratar esta realidad y la gestión de sus secuelas con una obra sumamente narrativa. En esta pieza -la taza como elemento de la cotidianidad- explora sus capacidades comunicativas y plásticas; un tratamiento prácticamente monocolor con engobe rosáceo enfatiza 
esa carnalidad, que sumada a la gestualidad de la forma se ve reforzada por los matices de tono, así como el gesto de las sutiles huellas dactilares en contraste con las crudas incisiones. Mientras que en la Figura 2 vemos un vaso donde se demuestra un mayor nivel de abstracción por parte del estudiante. En esta obra, perteneciente al ejercicio de pellizco, se aprecia la expansión de la esfera de barro original y su desarrollo hacia el cubo. La contundencia de la forma, ruda y arcaica, se ve atrayentemente reforzada por el uso monocolor de engobe azul, pero los finos cortes de líneas verticales equidistantes -que dejan entrever el material base- le proporcionan ritmo, elegancia y harmonía. En cambio, las Figuras 3 y 4 muestran dos piezas con una manera de construir la forma más orgánica. El uso de diferentes tipos de línea -zigzag, discontinua y ondulada- que se desarrollan por toda la superficie le confieren un carácter ornamental y decorativo, de vibración visual, a la vez que se imbrican con cierta ingenuidad aparente entre las manchas de color, de una gama reducida de engobe y de barro visto. Finalmente, en la Figura 5 una pieza realizada con cilindros de arcilla conforma una especie de cesta, relacionando formalmente el uso del material con otros campos del conocimiento y artesanías con una concepción objetual de continente, así como con el origen de estas. Cilindros de distinto grosor conforman la pieza que se va conformando según su posición; horizontales para el volumen central y verticales u onduladas para las asas. La esquematización y la apariencia frágil y variable de la pieza junto con la arcilla cocida, le confiere una sosegada expresividad.

\section{Conclusiones}

En el desarrollo de la práctica cerámica nos hemos percatado de algunas consideraciones que se han podido constatar en la entrega de las piezas y su relectura con las reflexiones escritas; en referencia a la idoneidad del uso de un vocabulario específico del conocimiento artístico y la necesidad de trabajarlo constantemente con alusiones visuales, la relación con una técnica tan abierta a la experimentación gestual y la proyección en un proceso extenso en el tiempo. Así pues, cabe destacar algunas afirmaciones verdaderamente lúcidas del alumnado que nos resultan de especial relevancia en esta creación con barro o cerámica:

(I) Primero de todo es esencial enfatizar en el hecho de concentrarse para crear y construir con las manos con un material como es la arcilla, cuyo intervalo de plasticidad es tan crítico que nos hace estar pendientes en todo momento de la humedad y del secado - por tanto de la necesidad o no de agua-, la presión y movimientos que ejercemos con los dedos o manos, y la evolución de aspecto y resistencia del material en crudo, seco y cocido. Siendo conscientes en todo momento de nuestras cualidades hápticas en pleno sentido holístico. (II) Se ha verificado la gestión emocional de enfrentarse a crear con un material con tantas características -nuevo para una parte considerable del alumnado-y la frustración o satisfacción por la asimilación de estas, como la aparición de grietas o roturas y su subsanación, la posibilidad de insistir con una materia sumamente dúctil o el gusto 
por el tacto de esta y su transformación. (III) También cabe señalar la conciencia de aprender a aprender, y que todo trabajo es estratégico, por ello la valía, implicación y resultado de la constancia. También incidir en el hecho de aprender a ver las obras en su conjunto - no solo un dibujo, una maqueta o una pieza-y poder valorar todo el trabajo y esfuerzo que conlleva, así como los pequeños detalles y sus significados. Se consigue así mantener esa emoción clave, que nos brinda un trabajo amplio que se va desarrollando en el tiempo y ampliándose en su complejidad, siempre proyectándose y abriendo por consiguiente múltiples campos cognitivos, sin encerrarnos en unos determinados que no puedan crecer ni apelar a otros campos de trabajo, que en el momento los estudiantes pudieran llegar positivamente a cohesionar. En todo esto la originalidad es el resultado de un proceso para el que se tiene que tener una finalidad en la obra misma (Alfaro, 2015). (IV) Y por último la capacidad de abstracción y su visión crítica de lo que se percibe a través de los sentidos en contraposición con la clave metamórfica de la cerámica y los elementos vitales: tierra, aire, agua y fuego.

Las piezas cerámicas realizadas por los estudiantes han tenido resultados sorprendentes, dispares cuanto a la confección. El tiempo ha sido prácticamente el mismo para los dos continentes, de hecho la pieza conformada a partir de pellizcos ha tenido mejores resultados que la realizada con churros y les ha llevado a experimentar y probar más formas y acabados. Este control del tiempo ha sido un factor clave para su desarrollo -así lo es especialmente en cerámica-, el aprovechamiento del aula y la estructura de la práctica han incidido en esta conciencia del tiempo y en la experiencia del espacio. En los momentos presentes, valores que son efímeros, fugitivos y contingentes entroncan con la necesidad de permanencia, igual como lo hace el arte y el artista, tratando de "destilar el eterno de lo transitorio" (Sennett, 2019, p.52). Así pues, también se necesita un equilibrio entre cambio y estabilidad, pues nuestra "fisiología humana se encuentra en la base de esta distinción. Cuando más deprisa te mueves, menos consciente eres de las peculiaridades" (Sennett, 2019, p.59). Esta disolución de la consciencia producida por la rapidez y la velocidad "define una cierta visión de la modernidad: si se va deprisa, se es libre; si se va poco a poco no" (Sennett, 2019, p.61), que saca a relucir esa cuestión inmanente de la cerámica y propia de lo contemporáneo: la de un tiempo vital que posibilite el aprendizaje y una verdadera transformación.

En general ha resultado una práctica muy interesante para la mayor parte del estudiantado y han valorado unas capacidades personales que creían ocultas, controlar la temporalidad que exige la práctica y los planteamientos estratégicos que son propios de la cerámica. También la importancia de trabajar con materiales tan dúctiles, mutables y con múltiples posibilidades expresivas, además de la forma y del color, y donde desarrollar la creatividad. Conocimientos propios de su entorno y técnicas que sean fáciles, sostenibles, económicas y con un sentido substancial de lo identitario, relacionando los útiles frecuentes con su sentido original y nuestra evolución histórica y cultural con la memoria de la humanidad. 


\section{Referencias}

Alborch, C. (2002). L'esforç per educar en l'art. En R. Huerta (ed.), Els valors de l'art a l'ensenyament (pp. 159-161). València: Universitat de València.

Alfaro, A. (2002). Art, artistes i educació. En R. Huerta (ed.), Els valors de l'art a l'ensenyament (pp. 23-26). València: Universitat de València.

Alcover, J.; Cebrián, T.; Navarro, E., y Medina, V. (1992). Territorio plural. Esculturas y proyectos. València: Obra Social i Cultural Bancaixa.

Berger, J. (2017). Mirar. Barcelona: Gustavo Gili.

Cabanellas, I. (2002). Raó i plaer en l'art. Dimensió estètica i educativa: l'estètica en l'art i en la vida. En R. Huerta (ed.), Art, artistes i educació. En R. Huerta (ed.), Els valors de l'art a l'ensenyament (pp. 51-57). València: Universitat de València.

Calvo, C. (1999). El fang. En Cerámica fin de siglo (pp. 124-127). València: Generalitat Valenciana.

De la Calle, R. (1999). L'altra cara de la ceràmica. En Cerámica fin de siglo (pp. 2-21). València: Generalitat Valenciana.

De la Villa, R. (2019). Salto de línea. En Sempere/Soledad Sevilla · Líneas Paralelas (pp. 2-9) Madrid: Galería Fernández-Braso.

Eliade, M. (2006). Mito y realidad. Barcelona: Kairós.

Ferrer, A. (2016). Un poniente abismal. En Miquel Navarro: Escultura íntima (pp. 54-65). Santo Tirso: Câmara Municipal de Santo Tirso.

Ferrer, A. (2019). "La fijeza es siempre momentánea": Juan David García Bacca, un mono gramático. En A. Ferrer (ed.), Re/incidencias 10: Juan David García Bacca (pp. 70-88). Quito: Centro Cultural Benjamín Carrión.

Fuster, J. (2015). Alfaro, un escultor con razones. En J. Martín y E. Rodríguez (eds.), Andreu Alfaro · En torno a la escultura: escritos y entrevistas (pp. 201-204). València: Universitat de València.

Gropius, W. (2019). Oskar Schlemmer: el teatro de la Bauhaus. Madrid: Casimiro. Kandinsky, V. (2010). De lo espiritual en el arte. Barcelona: Paidós.

Kellogg, R. (1979). Análisis de la expresión plástica del preescolar. Madrid: Cincel.

Pérez Camps, J. (1999). El segle de la ceràmica valenciana: de la indústria a l'art. En Cerámica fin de siglo (pp. 22-87). València: Generalitat Valenciana. 
Porcel, B. (2015). Andreu Alfaro y sus hierros enhiestos. En J. Martín y E. Rodríguez (eds.), Ob. cit. (pp. 205-212).

Sennett, R. (2019). Construir i habitar. Ètica per a la ciutat. Barcelona: Arcàdia.

Vicent, M. (1984). Llum i terror mineral d'Arcadi Blasco. En Arcadi Blasco: ceràmica, murs $i$ arquitectures per a defensar-se de la por, restes arqueològiques (pp. 5-7). Alacant: Caixa d'estalvis d'Alacant i Múrcia.

Yvars, J.F. (2012). Arabescos: entre la memoria y la experimentación. En Evarist Navarro: la construcción de la memoria (pp. 13-29). València: Institut Valencià d'Art Modern.

Yvars, J.F. (2012). Imatges amb enigma: la biblioteca d'Aby Warburg. Barcelona: Edicions 62. 